\title{
Review on Laboratory Mineral Soil Analysis and Soil Mineral Management in Organic Farming
}

\section{Dugasa Gerenfes}

Kulumsa Agricultural Research Center, Soil and Plant Analysis Laboratory, Assela, Ethiopia

\section{Email address:}

dgerenfes2017@gmail.com

\section{To cite this article:}

Dugasa Gerenfes. Review on Laboratory Mineral Soil Analysis and Soil Mineral Management in Organic Farming. International Journal of Bioorganic Chemistry. Vol. 6, No. 1, 2021, pp. 1-6. doi: 10.11648/j.ijbc.20210601.11

Received: February 7, 2021; Accepted: March 17, 2021; Published: March 30, 2021

\begin{abstract}
This review discusses about laboratory soil analysis and soil mineral management in different Organic farming. The objective of this review were laboratory mineral soil analysis and soil mineral management in organic farming was to draw together all the available relevant research findings in order to develop the knowledge and expertise of organic advisers and thereby to improve soil management practice on organic farms. There are several methods available for measuring total $\mathrm{N}$ in soils, mineral $\mathrm{N}$ in soils and mineralization potential. Chemical extractions which aim to establish the pool of nitrogen to plants include the use of potassium salts, $\mathrm{K}_{2} \mathrm{SO}_{4}$ to extract inorganic and labile organic $\mathrm{N}$ pools. Soil $\mathrm{P}$ tests are commonly used to assess soil nutrient availability and to assist in fertilizer recommendations. Available K measured by ammonium nitrate gave a good indication of the plant available $\mathrm{K}$ in soil; crops showed a response to increasing available $\mathrm{K}$ and continued cropping caused a decline in the pool of available $\mathrm{K}$ in soil. Soil analysis based on chemical analysis is a snapshot of nutrient pools. It is normally reported in $\mathrm{mg} / \mathrm{l}$ of soil. Soils are sampled and analysed and digital maps provided to the farmer. This then allows targeted use of inputs to correct nutrient deficiencies or acidity. While this is primarily used in conventional farming for fertiliser application it is now also being used increasingly in organic farming.
\end{abstract}

Keywords: Conventional, Extraction, K Pool, N Pool, Organic, P Pool

\section{Introduction}

The capacity to improve the fertility of a given soil through management was inextricably linked to the inherent properties of that site-soil texture, mineralogy, slope and climate. Ideally soil fertility should be assessed for the soil in situ, in the field/farm context, rather than as a list of properties of an isolated sample. Absolute requirements or critical values for any one factor of soil fertility considered alone would be almost impossible to determine, as the expression and interaction of properties in the field was the key to crop growth. It is particularly important to have a good understanding of the inherent properties of any site when farming organically as the scope for using agrochemicals to overcome short-term problems was severely restricted compared with conventional systems. In this respect maintaining good soil structure was paramount in organic production. compaction, for example, can result in poor root development and thus poor nutrient uptake. In conventional systems this can be at least partially overcome through the application of soluble fertilisers. Organic farming requires the preventative approach of aiming to ensure that soil structure does not limit production [1].

Traditionally soil fertility has been equated with soil nutrient availability, assessed through chemical analysis, but increasingly physical and biological parameters were included in assessments of soil fertility [2]. It was also interesting to note that measurement of one soil property can provide a good indication of other properties. For example, i) $\mathrm{pH}$ can be used as an indicator of biological activity or ii) water filled pore space could be used as an indicator of methane or nitrous oxide production. Soil tests provide the information necessary to plan and manage successful crop and livestock production on the farm. Soil tests were only as representative of the soil conditions as the samples collected. Thus samples sent to the laboratory should be truly representative of the field and be a well-mixed composite of at least 10-15 subsamples. If a field includes more than one very different soil type it was probably worth getting samples from different parts of the field analysed separately. Stone 
content should also be taken into account in interpreting the analysis. Soil analysis was generally reported in $\mathrm{mg} / \mathrm{L}$ of nutrient in the soil and often described using an index. A oneoff soil analysis simply provides a snapshot of nutrient availability at a particular time. It was thus critical to repeat soil analysis at regular intervals to identify trends in nutrient availability and thus adjust nutrient management accordingly. This was particularly important for organic farmers in order to assess the benefits of slow release of nutrients from crop residues and imported materials. Similarly the analysis itself is only the first step, specialist interpretation and recommendations are equally important.

There has been considerable discussion over whether alternative methods of chemical soil analysis are required for organic farming. Conventional soil analysis for advisory purposes relies on the interpretation of the chemical extraction of different soluble nutrient pools from the soil to predict nutrient availability to crops [3]. A wide range of approaches are used even in conventional systems with at least 12 different soil extractants used for measuring available $\mathrm{P}$ in soils [4]. However, in organic systems it is the release of these nutrients by biological processes from organic matter pools that is critical in determining nutrient availability. Organic systems differ very significantly from conventional systems in that they depend very much more on the application of nutrients in insoluble or organic compounds. It is therefore often the rate of transfer from an unavailable to available nutrient form that is critical in organic systems rather than the size of the available nutrient pool. When comparing farming systems, measurement method may affect the results; routine soil testing may not be able to predict available soil $\mathrm{P}$ in a biodynamic system due to the interaction of crop and soil factors in controlling mobility of $\mathrm{P}$ ions [1].

Based on the above justification the objective of this review was to draw together all the available relevant research findings in order to develop the knowledge and expertise of organic advisers and thereby to improve soil management practice on organic farms. The Review will concentrate on $\mathrm{N}, \mathrm{P}$ and $\mathrm{K}$ : Identify all the relevant research undertaken and summarise the conclusions in a form that is easily accessible and can be used to help them select appropriate soil analytical techniques and to interpret the results and provide practical advice to farmers on soil management and amendments.

\section{Review of Literature}

\subsection{Soil N Pools}

The layers of mineral soil exploited by plant roots generally contain between 5000 and 15,000 kg N/ha (around $5 \%$ of dry weight or organic matter). Total soil $\mathrm{N}$ content is thus strongly linked to soil organic matter content However, the majority of this $\mathrm{N}$ is in organic forms which are not plant available. Figure 1 shows the relationships between different $\mathrm{N}$ pools. Generally around $1-2 \%$ or the organic nitrogen in soil is mineralized and available to crops in inorganic forms (nitrate and ammonium). At low $\mathrm{pH}$, ammonium is the dominant form. The soil nitrogen cycle is very dynamic and the nitrogen held in microbial biomass cycles constantly. The conversion of organic to inorganic forms is stimulated by cultivation. In organic systems the largest quantities of available $\mathrm{N}$ follow ploughing of leys. Available nitrogen which is not taken up by plants is subject to gaseous and leaching losses.

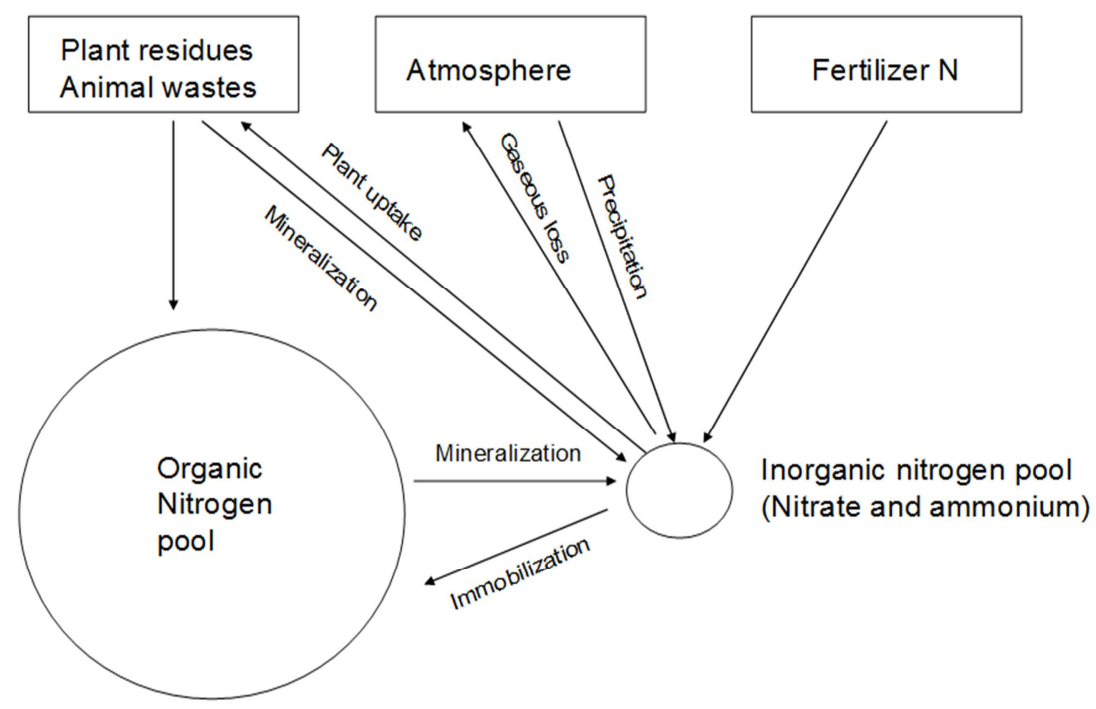

Figure 1. N pools, sources and transfers [5].

\subsection{Soil P Pools}

The total level of native $\mathrm{P}$ in soil is low compared to other plant nutrients. It is usually present in amounts equivalent to one tenth to one quarter that of $\mathrm{N}$ and one twentieth that of $\mathrm{K}$ [6]. The total $\mathrm{P}$ content of soil varies greatly, ranging from 500 to $2,500 \mathrm{~kg} \mathrm{ha}^{-1}$, much of this $(15-70 \%)$ is present in strongly adsorbed or insoluble inorganic forms with the remainder present in organic forms [7]. In organic soils, such 
as peat and forest soils, a larger proportion of $\mathrm{P}$ will be present in organic compounds. The amount of $\mathrm{P}$ in the soil is related to a number of factors, including $\mathrm{P}$ inputs, soil parent material and management.

Levels of $\mathrm{P}$ in the soil solution at any one time are much less than that required for plant growth. Therefore, levels of $\mathrm{P}$ in the soil solution must be constantly replaced from the inorganic and organic parts of the soil or in managed systems by fertiliser and manure additions. Soil $\mathrm{pH}$ is one of the main factors controlling the forms of inorganic $\mathrm{P}$, with the quantities of $\mathrm{Al}, \mathrm{Fe}, \mathrm{Mn}$ and $\mathrm{Ca}$ determining the amounts of these forms. A pH between 6 and 7 gives greatest $\mathrm{P}$ availability. This relationship is shown in Figure 2.

Organic P compounds include inositol phosphates, nucleic acids and phospholipids. Additionally the soil microbial biomass also contains a significant pool of organic $\mathrm{P}$ within its cells. In arable soils, approximately $3 \%$ of the total soil organic $\mathrm{P}$ is present in the microbial biomass $(6-27.5 \mathrm{mg} \mathrm{P}$ $\mathrm{kg}^{-1}$ soil). In grassland soils, the biomass comprises a larger $(5-24 \%)$ proportion of the total soil organic $\mathrm{P}$, equivalent to 12 - $72 \mathrm{mg} \mathrm{P} \mathrm{kg}^{-1}$ soil [8].

Soil $\mathrm{P}$ transformations are complex. $\mathrm{P}$ dynamics in soil are often illustrated by dividing $\mathrm{P}$ into different pools based on the availability of the various forms, usually defined by chemical extracts (Figure 3). More details of the chemical extracts are given below. Phosphorus is also added or returned to the soil in crop residues, fertilisers (inorganic and organic), deposition (wet and dry), animal and human wastes. The inorganic P applied to soils is either taken up by plants, or becomes weakly (physical) or strongly (chemical) adsorbed onto $\mathrm{Al}, \mathrm{Fe}$ and $\mathrm{Ca}$ surfaces, or built into organic $\mathrm{P}$. An equilibrium exists between soil solution $\mathrm{P}$ and labile inorganic $\mathrm{P}$, as inorganic $\mathrm{P}$ is removed from the soil by plants or immobilisation processes, the inorganic $\mathrm{P}$ is solubilised from the labile inorganic $\mathrm{P}$ pool. At any one time, only about $0.01 \%$ of the total $\mathrm{P}$ is present in an available form [6].

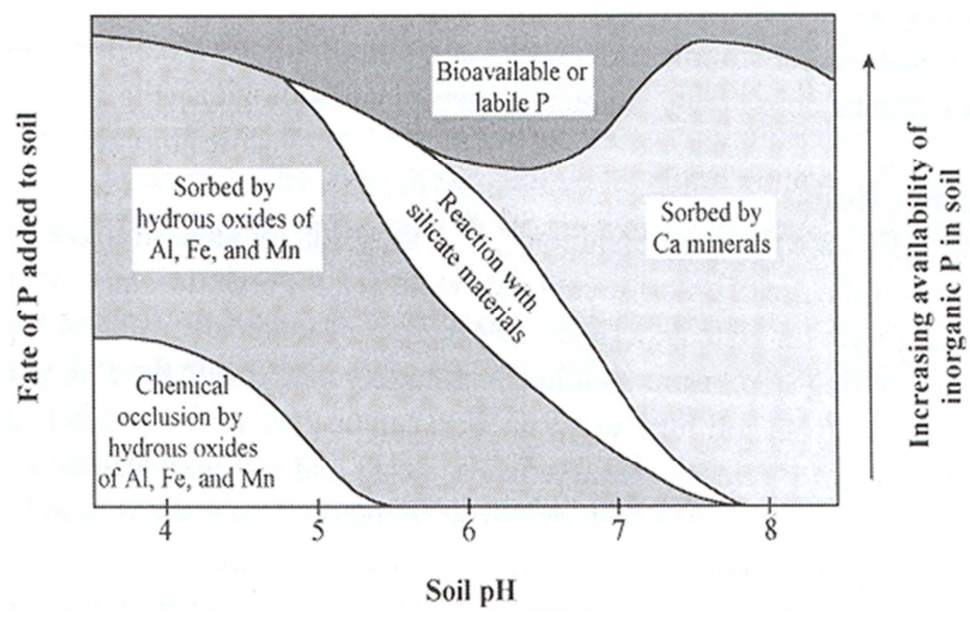

Figure 2. Approximate representation of the fate of $P$ added to soil by sorption and occlusion in organic forms, as a function of soil pH (Source: [9].

The mineralization of organic matter by soil micro-organisms provides an important supply of available P. [10] estimated that the annual turnover of organic $\mathrm{P}$ through the soil microbial biomass was $25 \mathrm{~kg} \mathrm{P} \mathrm{ha}^{-1}$ for grassland and $<1$ to $10 \mathrm{~kg} \mathrm{P} \mathrm{ha}^{-1}$ for soils under arable crops or under ley arable rotations. More rapid turnover of microbial biomass $\mathrm{P}$ has also been measured in soils receiving FYM regularly [11]. It has been shown that mineralization of organic $\mathrm{P}$ is greater when available $\mathrm{P}$ is limited [12]. Some groups of micro-organisms also secrete organic acids that attack and release $\mathrm{P}$ from insoluble forms of phosphate. The microbial biomass, therefore, has a key role in the cycling of $\mathrm{P}$ through the soil solution.

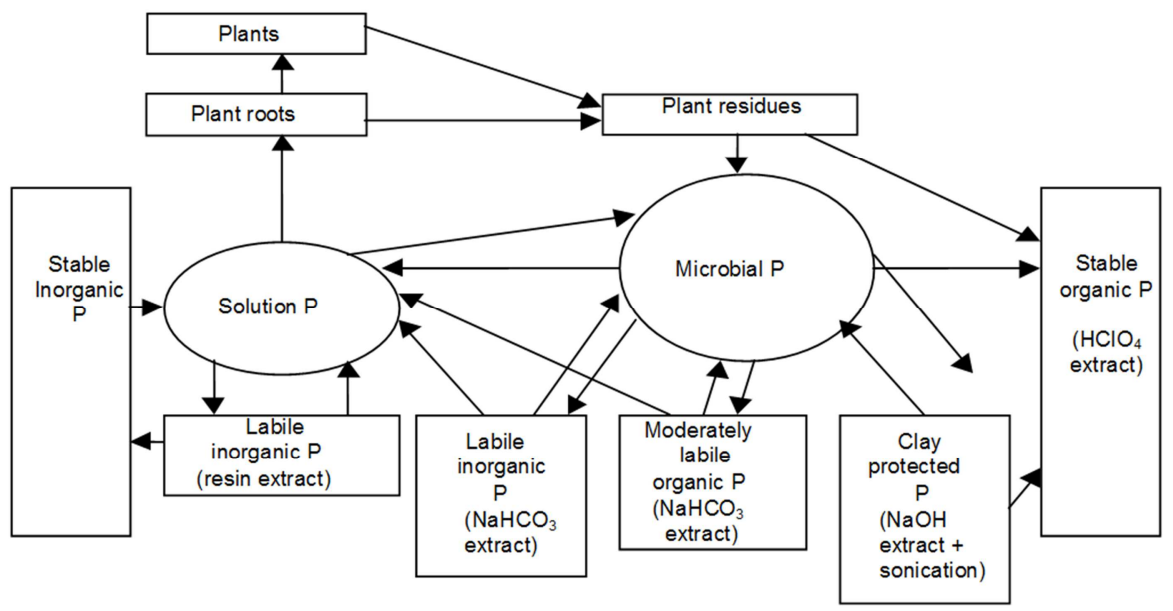

Figure 3. Soil P transformations. 


\subsection{Soil K Pools}

Large reserves of $\mathrm{K}$ are present in many soils. The $\mathrm{K}$ content of mineral soils can vary from 0.04 to $3 \%$ (1000 to $75,000 \mathrm{~kg} \mathrm{ha}^{-1}$ ) [13]. Of this, $90-98 \%$ is bound in the mineral form and $2 \%$ is present in the soil solution and exchangeable phases. Potassium exists in four forms in soils, these forms differ in their availability to plants and microbes: solution $>$ exchangeable $>$ fixed $>$ structural (native/mineral $/$ matrix) (Figure 4). The fixed pool alone or fixed plus structural $\mathrm{K}$ are often referred to as non-exchangeable $\mathrm{K}$.

According to (Brady and Weil, 1999) $<0.1 \%$; levels of $\mathrm{K}$ in the soil solution are generally low unless recent additions of $\mathrm{K}$ have been made. Plant available $\mathrm{K}$ exists in two forms, as $\mathrm{K}$ ions in soil solution and exchangeable $\mathrm{K}$. Soil solution $\mathrm{K}$ is the most readily available source of $\mathrm{K}$ to plants and microbes and is the form most subject to leaching. [14] Estimated that only $5 \%$ of the $\mathrm{K}$ requirement of a crop is present in the soil solution at any one time. The concentration of $\mathrm{K}$ ions in the soil solution depends on a variety of factors including soil type, soil weathering, and fertiliser use and cropping.

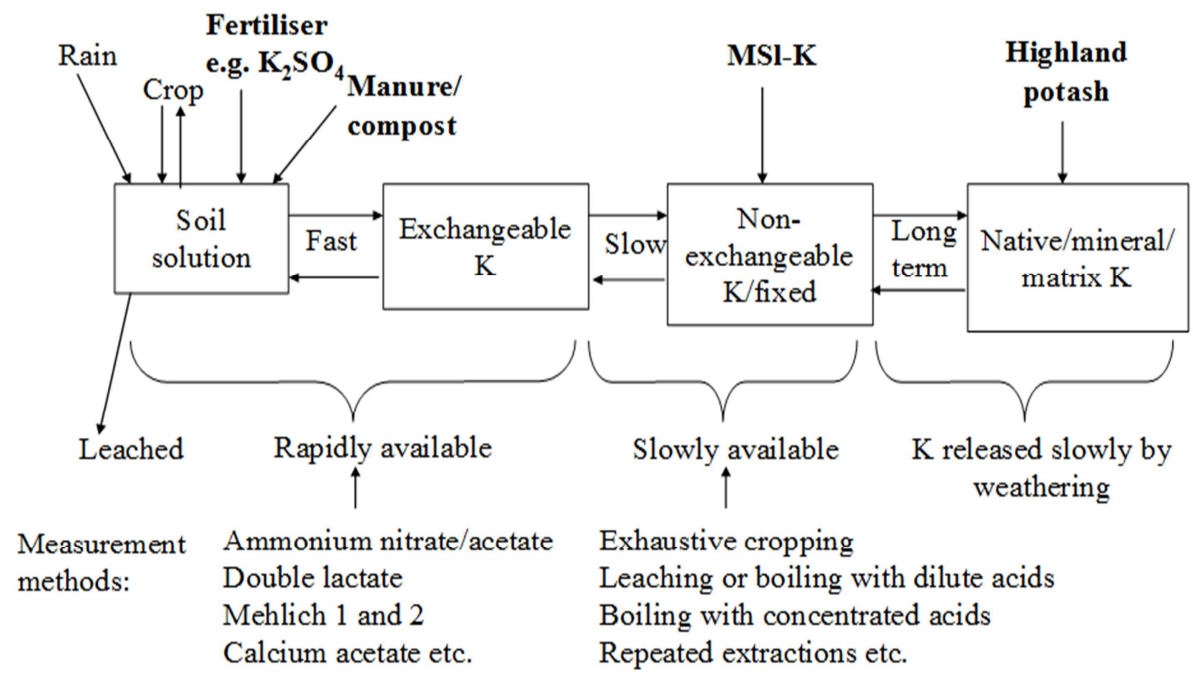

Figure 4. Dynamic equilibrium of soil K showing K extracted by different analytical techniques.

As plants and microbes remove $\mathrm{K}$ from the soil solution some of the exchangeable $\mathrm{K}$ moves into the soil solution until the equilibrium is re-established. If soluble $\mathrm{K}$ fertilizers' are added to the soil, the soil solution becomes enriched and the process operates in reverse, with $\mathrm{K}$ moving from solution onto the exchange complex. It is generally not possible to decrease exchangeable $\mathrm{K}$ levels below a certain level because as exchangeable $\mathrm{K}$ is reduced, the remaining $\mathrm{K}$ is held more strongly against further solubilisation and the release of $\mathrm{K}$ is triggered from non-exchangeable forms to replenish the exchangeable pool. Some clay minerals contain adsorption sites (wedge sites) which have a high specificity for K. Fixed $\mathrm{K}$ is usually described as being moderately to sparingly available to plants, with availability dependent on the plant species; monocotyledons are better able to utilise fixed $\mathrm{K}$ than dicotyledons, due to differences in their root system [15]. The release and fixation of $\mathrm{K}$ can be seen as a dynamic and reversible process (Figure 3). Potassium release and fixation in soils is governed mainly by the quantities and type of primary and secondary minerals present in the soil, their particle size and $\mathrm{K}$ activity around the minerals [16]. It is also affected by factors such as soil $\mathrm{pH}$, rainfall and temperature, wetting and drying, freezing and thawing, soil structure, fertilization and plant roots. In natural ecosystems most of the $\mathrm{K}$ is recycled in this way, however, in agricultural systems, one fifth (e.g. cereal grains) or practically all (e.g. hay) the $\mathrm{K}$ will be removed from the system. Some $\mathrm{K}$ will also be lost in runoff, leaching or erosion.

\section{Discussions}

\subsection{Methods of Measuring Soil N}

There are several methods available for measuring total $\mathrm{N}$ in soils, mineral $\mathrm{N}$ in soils and mineralization potential. Chemical extractions which aim to establish the pool of nitrogen to plants include the use of potassium salts e.g. $\mathrm{KCl}$ or $\mathrm{K}_{2} \mathrm{SO}_{4}$ to extract inorganic and labile organic $\mathrm{N}$ pools. The problem with these is that they are simply a snapshot of what $\mathrm{N}$ is available at a given point in time rather than what will be available over the growing season. This is primarily because mineralization is so strongly influenced by weather conditions. Rainfall is particularly important because nitrate moves in water and thus availability to plants is restricted in dry soil conditions. Soil $\mathrm{N}$ is also very variable spatially particularly in grazed situations or under pigs and poultry. Incubation methods are also generally too time consuming for routine use. In the conventional sector there is interest in retrospective methods which analyse $\mathrm{N}$ in plant material as a basis for fertiliser application but this is much less relevant in organic farming. Regular measurement of soil organic matter using, for example, loss on ignition which provide guidance 
on fluctuations in soil organic matter over time and thus total soil nitrogen levels.

\subsection{Methods of Measuring Soil P}

Soil $\mathrm{P}$ tests are commonly used to assess soil nutrient availability and to assist in fertiliser recommendations. A large number of soil $\mathrm{P}$ tests exist, with more than ten different methods available. Other tests for available $\mathrm{P}$ such as Mehlich [17, 18] and Bray [19] are widely used in the US and world-wide. However, in most countries one or two tests are favoured [4]. No single test is suitable for all soil types and each soil test has its limitations. There have been many reviews discussing the various soil $\mathrm{P}$ tests and their relative merits (e.g. [20,9]. The main criticisms of many of the soil tests is that they fail to give information on the rate of conversion of insoluble $\mathrm{P}$ forms to plant available forms during the growing season [21] and do not provide information about the availability of organic forms of $\mathrm{P}$.

The Olsen-P test [22] is a useful method for predicting $\mathrm{P}$ availability in calcareous, alkaline or neutral soils and is the most commonly used $\mathrm{P}$ method. The Olsen reagent extracts $\mathrm{P}$ through a combined $\mathrm{pH}$ and ion effect, removing phosphate in solution, plus some labile solid phase P compounds (e.g. phosphate adsorbed to free $\mathrm{CaCO}_{3}$ ), slightly soluble calcium phosphate precipitates, and phosphate loosely sorbed to $\mathrm{Al}$ and Fe oxide surfaces [23]. The extraction also solubilises some of the soil organic $\mathrm{P}$, this is important as it is believed to provide a measure of the potential supply of soil organic $\mathrm{P}$ to plant uptake. The use of water or a dilute salt solution, such as $0.01 \mathrm{M} \mathrm{CaCl}_{2}$, can be used to determine the $\mathrm{P}$ concentration of the soil solution. This method has been employed successfully for fertiliser recommendations under certain soil and crop conditions. More recently, $\mathrm{CaCl}_{2}$ extractable $\mathrm{P}$ has been used as an indicator of the risk of $\mathrm{P}$ loss from soil to water [21].

The application of fertilisers with a low solubility, e.g. rock phosphate, may lead to the build-up of residual fertiliser in the soil that is not measured by standard soil P tests. There is a need to consider methods that predict the long-term release of nutrients from these sources. However, extracting solutions may not be suitable for evaluating available $\mathrm{P}$ when they also remove $P$ from the rock phosphate, which under natural conditions, would not become available for plant growth [24].

\subsection{Methods of Measuring Soil K}

A number of methods are available for measuring soil $\mathrm{K}$. Potassium exchangeable to an ammonium salt solution is the most commonly used estimate of plant available K [16]. Soil K status measured using ammonium nitrate normally increases during the winter, due to a change in soil equilibrium conditions resulting from reduced crop uptake and freeze-thaw effects causing fixed $\mathrm{K}$ to be released from the clay mineral matrix. Sandy soils are less affected by seasonal changes but may have reduced levels in late summer [25].

Table 1. Methods for measuring soil K [16].

\begin{tabular}{|c|c|}
\hline K fraction & Method \\
\hline \multirow[t]{3}{*}{ Solution } & Batch equilibration or leaching with water \\
\hline & Extraction by pressure membrane or centrifugation \\
\hline & Activity ratios \\
\hline \multirow{7}{*}{ Exchangeable } & Batch equilibration or column leaching with dilute solutions of salts (especially $\mathrm{NH}_{4}{ }^{+}$) and acids (citric, nitric) \\
\hline & Electroultrafiltration \\
\hline & Bray 1 \\
\hline & Mehlich 1 and 2 \\
\hline & Potassium potentials \\
\hline & Calcium acetate lactate \\
\hline & Ammonium bicarbonate + DPTA \\
\hline \multirow[t]{4}{*}{ Non-exchangeable } & Exhaustive crossing \\
\hline & Leaching with dilute acids and salts \\
\hline & Boiling with dilute or concentrated acids \\
\hline & Hot $\mathrm{MgCl}_{2}$ \\
\hline Mineral & Selective dissolution with Na-pyrosulphate fusion \\
\hline
\end{tabular}

\section{Summary}

Soil analysis should be carried out at regular intervals to provide a picture of changes over time. It also needs to be interpreted within the context of a rotation, particularly timing of soil analysis with respect to growing crops known to remove significant amounts of nutrients. Getting a representative sample was very important. Samples sent to the laboratory should be well mixed composites of 10-15 subsamples. If a field includes more than one very different soil type it is probably worth getting samples from different parts of the field analysed separately. Different extract ants would give different information. Available $\mathrm{K}$ measured by ammonium nitrate gives a good indication of the plant available $\mathrm{K}$ in soil on most soils. The $\mathrm{P}$ index system commonly used cannot be simply applied in organic farming due to the complex interactions between chemical and biological pools and processes. Soil maps can provide useful information with respect to identifying likely trace element and potassium deficiency. Soil organic matter changes over time provide a useful indicator of total $\mathrm{N}$ in soil. Currently 
available measurements of available $\mathrm{N}$ and potentially available $\mathrm{N}$ are expensive and of little practical value in organic farming.

\section{References}

[1] Oborn I., Edwards A. C., Witter E., Oenema O., Ivarsson K., Withers PJA., et al. 2003. Element balances as a tool for sustainable nutrient management: a critical appraisal of their merits and limitations within an agronomic and environmental context. European Journal of Agronomy 20: 211-225.

[2] Stockdale EA, Shepherd MA, Fortune S and Cuttle SP. 2002. Soil fertility in organic farming systems - fundamentally different? Soil Use and Management 18: 301-308.

[3] Edwards A. C., Withers P. J. A., Sims T. J. 1997. Are current fertiliser recommendation systems for phosphorus adequate? Proceedings of the International Fertiliser Society 404: 1-23.

[4] Tunney H, Csathó P and Ehlert P. 2003. Approaches to calculating $\mathrm{P}$ balance at the field-scale in Europe. Journal of Plant Nutrition and Soil Science 166: 1-9.

[5] Brady N. C. 1990. The Nature and Properties of Soils. $10^{\text {th }}$ Edition. Macmillan Publishing, New York.

[6] Brady N. C. and Weil R. R. 1999. The Nature and Properties of Soils, 12th Edition. Prentice-Hall Inc. New Jersey. pp. 540584 .

[7] White R. E. 1995. Introduction to the Principles and Practice of Soil Science. $2^{\text {nd }}$ Edition. Blackwell Science, UK.

[8] Brookes P. C., Powlson D. S. and Jenkinson D. S. 1984. Phosphorus in the soil microbial biomass. Soil Biology and Biochemistry 16: 169-175.

[9] Sharpley A. 2000. Phosphorus Availability. In: Handbook of Soil Science. Sumner M. E. (ed), CRC Press. Boca Raton Florida. pp. D18-D37.

[10] Chater M. and Mattingly G. E. G. 1980. Changes in organic phosphorus contents of soils from long continued experiments at Rothamsted and Saxmundham. Rothamsted Experimental Station Report. 1979, Part 2: 41-61.

[11] Oberson A., Besson J. M., Maire N. and Sticher H. 1996. Microbiological transformations in soil organic phosphorus transformations in conventional and biological cropping systems. Biology and Fertility of Soils 21: 138-148.

[12] Smeck N. E. 1985. Phosphorus dynamics in soils and landscapes. Geoderma 36: 185-199.
[13] Cresser M., Killham K. and Edwards T. 1993. Soil chemistry and its applications. Cambridge Environmental Chemistry Series 5. Cambridge University Press. Cambridge.

[14] McLean E. O. and Watson M. E. 1985. Soil Measurements of Plant-Available Potassium. In: Potassium in Agriculture. Munson R. D. (ed). ASA, CSSA, SSSA. Madison, Wisconsin. p. 277-308.

[15] Mengel K. 1985. Dynamics and availability of major nutrients in soils. Advances in Soil Science 2: 65-131.

[16] Goulding K. W. T. 1987. Potassium fixation and release. In: Methodology in soil-K research. Proceedings of the $20^{\text {th }}$ Colloquium of the International Potash Institute. Baden bei Wien, Austria.

[17] Nelson W. L., Mehlich A. and Winters E. 1953. The development, evaluation and use of soil tests for phosphorus availability. In: Soil and Fertilizer Phosphorus. Pierre W. H. and Norman A. G. (eds). Agronomy No. 4. American Society of Agronomy, Madison, Wisconsin, pp. 153-188.

[18] Mehlich A. 1984. Mehlich 3 soil test extractant: a modification of Mehlich 2 extractant. Communications in Soil Science and Plant Analyses 15, 1409-1416.

[19] Bray R. H. and Kurtz L. T. 1945. Determination of total, organic and available forms of phosphorus in soils. Soil Science 59: 39-45.

[20] Sibbesen E. 1983. Phosphate soil tests and their suitability to assess the phosphate status of soil. Journal of Science of Food and Agriculture 34: 1368-1374.

[21] Stevenson F. J. 1986. The Phosphorus Cycle. In: Cycles of Soil, Carbon, Nitrogen, Phosphorus, Sulfur, Micronutrients, John Wiley and Sons Inc, New York, pp. 231-284.

[22] Olsen S. R., Cole C. V., Watanabe F. S. and Dean L. A. 1954. Estimation of available phosphorus in soils by extraction with sodium bicarbonate. Circular No. 939. US Dept. of Agriculture.

[23] Schoenau J. J. and Karamanos R. E. 1993. Sodium bicarbonate-Extractable P, K, N. In: Soil Sampling and Methods of Analysis Carter M. R. (ed). Canadian Society of Soil Science. Boca Raton, Fla., Lewis. Canada. pp. 51-58.

[24] Benbi D. K., Gilkes R. J. and Bolland M. D. A. 1988. An assessment of soil tests for phosphate for the prediction of cereal yields on a sandy soil in Western Australia. Fertiliser Research 16: 137-155.

[25] Collins C. and Budden A. L. 1998. Soil analysis techniques The need to combine precision with accuracy. Proceedings of the International Fertiliser Society. 418. 